\title{
A NEW HYBRID MODEL FOR EVALUATING THE WORKING STRATEGIES: CASE STUDY OF CONSTRUCTION COMPANY
}

\author{
Mohammad Majid Fouladgar ${ }^{1}$, Abdolreza Yazdani-Chamzini², \\ Edmundas Kazimieras Zavadskas ${ }^{3}$, S. Hamzeh Haji Moini ${ }^{4}$
}

\author{
${ }^{1,2,4}$ Fateh Research Group, Department of Strategic Management, Milad Building, Mini city, \\ Aghdasieh, Tehran, Iran \\ ${ }^{3}$ Faculty of Civil Engineering, Vilnius Gediminas Technical University, \\ Sauletekio al. 11, LT-10223 Vilnius, Lithuania \\ E-mails: ${ }^{1}$ manager@fatehidea.com; ${ }^{2}$ a.yazdani@fatehidea.com; \\ 3edmundas.zavadskas@vgtu.lt (correspondingauthor); ${ }^{4}$ smhpm85@yahoo.com
}

Received 04 July 2011; accepted 15 November 2011

\begin{abstract}
Selection of the working strategy is a critical problem and it plays a significant role in the success of organization development. On the other hand, selecting the most appropriate working strategy among a pool of alternatives is a multi-criteria decision making (MCDM) problem. Since every working strategy has its benefits and costs and may bring a company different opportunities and risks, which kind of working strategy is the most appropriate for a company to accomplish is a sophisticated and complex decision with a high degree of uncertainty. Therefore, the current paper proposed an integrated evaluation model based on the analytic network process (ANP) and the complex proportional assessment (COPRAS), to help the decision makers or managers with the selection of proper working strategy in a fuzzy environment where the fuzziness and uncertainties are handled with linguistic terms parameterized by triangular fuzzy numbers (TFNs). In this paper fuzzy ANP (FANP) is utilized to take into account interdependence and dependencies and determine the importance weights of benefit, opportunities, cost and risk (BOCR) factors, and fuzzy COPRAS is applied to rank the alternatives. To show the potential application of the proposed model, a real world application is conducted to illustrate the use of the proposed model for the working strategy selection problem. The results show the capability and effectiveness of the proposed model.
\end{abstract}

Keywords: fuzzy ANP, fuzzy COPRAS, BOCR, working strategy, construction company.

Reference to this paper should be made as follows: Fouladgar, M. M.; Yazdani-Chamzini, A.; Zavadskas, E. K.; Haji Moini, S. H. 2012. A new hybrid model for evaluating the working strategies: case study of construction company, Technological and Economic Development of Economy 18(1): 164-188.

JEL Classification: C02, C44, C54, D81, M11, M20, L16, L74, P11, P41. 


\section{Introduction}

Companies require managing their organizational resources to be equipped in facing with an ever-increasingly competitive and changeable environment. The process of working strategy refers to the procedures which can be used to develop working strategies in future. For this reason, companies should determine the pattern of strategic decisions and actions which set the role, objectives and activities of developing in the future. Therefore, the appropriate working strategy plays a significant role in increasing benefit, promoting the sustainability of company, minimizing risk, improving credibility and as a result achieving organizational goals and objectives. For achieving the aim, various strategic alternatives should be evaluated to the best ones be selected. This process is complex and challenging because various qualitative and quantitative criteria may affect each other mutually (Vahdani, Hadipour 2010).

The merit of using multicriteria decision making (MCDM) methods is their ability to solve complex and sophisticated problems. The MCDM methods provide powerful tools for determining the best alternative among the feasible alternatives according to the evaluation criteria. These methods are recommended as being helpful in reaching important decisions that cannot be determined in a straightforward manner (Wu et al. 2010).

The complexity of working systems makes it difficult to comprehensively manage such system by the help of a single set of guidelines. Application of a suitable decision process can help decision makers to reduce decision failures. The analytic network process (ANP), which is an extension of analytic hierarchy process (AHP), is a powerful methodology that deals with dependence and feedback (Saaty 1996). Despite the fact that many conventional MCDM methods are based on the independence assumption, the ANP technique takes into account the dependence assumption among individual criteria that is more adapted with real world application.

The reasons for using an ANP-based decision analysis approach are: (1) ANP can measure all tangible and intangible criteria in the model (Saaty 1996), (2) ANP is a relatively simple, intuitive approach that can be accepted by managers and other decision-makers (Presley, Meade 1999), (3) ANP allows for more complex relationship among the decision levels and attributes as it does not require a strict hierarchical structure (Yazgan et al. 2010), and (4) ANP is more adapted with real world problems.

However, taking into account the aspects of BOCR of an alternative, including the positive and negative criteria all together, helps decision makers to fulfill a more comprehensive way in real problems.

The ANP with BOCR has been successfully employed in many different fields (Table 1).

It is clear that the ANP with BOCR has demonstrated its capabilities and efficiencies as a practical management and decision making tool.

Another popular method to solve MCDM problems is the COPRAS (COmplex PRoportional Assessment) technique which was introduced by Zavadskas and Kaklauskas (1996). This technique is employed by different researchers in order to solve many various problems (Table 2), because this method includes some advantages which are not limited to, as follows: (1) COPRAS allows simultaneous consideration of the ratio to the ideal solution and the ideal-worst solution, (2) simple and logical computations, and (3) results are obtained in shorter time than other methods such as AHP and ANP. 
Table 1. Recent application of ANP with BOCR

\begin{tabular}{ll}
\hline \multicolumn{1}{c}{ Reference } & \multicolumn{1}{c}{ Considered problem } \\
\hline Begičević et al. 2010 & Prioritization of projects \\
\hline Chen et al. 2010 & Strategic selection of management systems \\
\hline Yazgan et al. 2010 & Balanced scorecard \\
\hline Lee et al. 2010 & Model for production strategy \\
\hline Lee et al. 2011 & Model for power industry \\
\hline Bottero et al. 2011 & Wastewater treatment systems \\
\hline Bobylev 2011 & Environmental impact of construction technologies \\
\hline
\end{tabular}

Table 2. Recent application of COPRAS

\begin{tabular}{lll}
\hline \multicolumn{1}{c}{ Reference } & \multicolumn{1}{c}{ Method } & \multicolumn{1}{c}{ Considered problem } \\
\hline Kaklauskas et al. 2010 & COPRAS & Complex analysis of intelligent built environment \\
\hline Tupenaite et al. 2010 & COPRAS & Assessment of alternatives for renovation \\
\hline Zolfani Hashemkhani et al. 2011 & COPRAS-G & Forest roads locating \\
\hline Antucheviciene et al. 2011 & COPRAS-F & $\begin{array}{l}\text { Comparative analysis fuzzy VIKOR, fuzzy TOPSIS } \\
\text { and COPRAS-F methods }\end{array}$ \\
\hline Chatterjee et al. 2011 & COPRAS & Materials selection \\
\hline Chatterjee and Chakraborty 2011 & COPRAS-G & Materials selection \\
\hline Kildiene et al. 2011 & COPRAS & Analysis of construction sector in the time of crisis \\
\hline Maniya and Bhatt 2011 & COPRAS & Selection of flexible manufacturing systems \\
\hline Medineckiene and Björk 2011 & COPRAS & Preferences regarding renovation measures \\
\hline Yazdani et al. 2011 & COPRAS-F & Risk analysis of critical infrastructures \\
\hline
\end{tabular}

The MCDM methods are successfully applied to solve certain problems. But, these techniques are less effective in conveying the imprecision and fuzziness characteristics (Bashiri et al. 2011). Zavadskas and Antucheviciene (2007) used first generation fuzzy COPRAS (COPRAS-F) for multiple criteria evaluation of rural buildings regeneration alternatives. Zavadskas et al. (2008) used COPRAS method for selection of the effective dwelling house walls by applying attributes values determined at intervals (COPRAS-G).

However, a large amount of uncertainty is connected with various factors of working strategies, and consequently there is a need of fuzzy theory to handle the existing uncertainty. Fuzzy set theory is a powerful mathematical tool to solve problems in presence of uncertainty that is normally found in strategy selection processes.

For this reason, a well designed decision process is needed to help decision makers to reduce decision failures.

The main objective of the current study is to model the working strategy decision-making problem as a MCDM problem and provide a ten-step decision support framework to carefully evaluate working strategies. For achieving the aim, the fuzzy ANP method is employed to obtain the relative weights of BOCR criteria but not the entire evaluation process to reduce the large number of pairwise comparison. For this reason, fuzzy COPRAS is used to calculate 
the performance of alternatives, and to prioritize the working strategies in terms of their overall performance on evaluation main and sub-criteria.

The rest of this paper is organized as follows. Section 2 describes fuzzy theory, including fuzzy logic, fuzzy number, and linguistic terms. Section 3 goes over the key concepts of fuzzy analytic network process (FANP). Section 4 describes the basics of the fuzzy COPRAS. The proposed model is presented in Section 5. Section 6 provides a case study of Fateh Construction Company to demonstrate the potential application of the proposed model. In order to evaluate the stability of the results a sensitivity analysis of BOCR factors is discussed in Section 7. Discussions and conclusions are provided in the last section.

\section{Fuzzy theory}

Fuzzy theory first was developed by Zadeh (1965) to handle the inherent uncertainty and imprecision associated with information concerning different parameters. Fuzzy theory enables decision makers to tackle the ambiguities involved in the process of the linguistic assessment of the data (Önüt et al. 2009).

A fuzzy set is defined by a membership function, which determines to each element a grade of membership within the interval $[0,1]$. If an element $x$ fully belongs to a set $\mathrm{A}, \mu_{A}(x)=1$, and if an element $x$ does not belong to the set under consideration, $\mu_{A}(x)=0$. The higher is the membership value, the greater is the belongingness of an element $x$ to the set $A$.

A triangular fuzzy number (TFN) can be denoted as $\tilde{A}=(l, m, u)$ and its membership function $\mu_{A}(x)$ can be defined asfollows:

$$
\mu_{A}(x)= \begin{cases}(x-l) /(m-l) & l \leq x \leq m \\ (x-u) /(m-u) & m \leq x \leq u \\ 0, & \text { otherwise }\end{cases}
$$

where $l, m$, and $u$ stand for the lower, middle, and upper value of the support of $\tilde{A}$, respectively, and $l \leq m \leq u$.

The fuzzy linguistic term is a fuzzy number or a variable whose values are words or sentences in language terms. These terms can be divided into miscellaneous linguistic criteria. We deliberately select a 9-point scale for defining the importance weights of the main criteria (BOCR factors) and evaluation indicators which take part in the second and third levels of hierarchical model, depicted in Fig. 4. Linguistic terms for the weights of the BOCR factors and evaluation indicators are depicted in Table 3. As seen in Table 3, the weights of the BOCR factors and evaluation indicators are calculated by pairwise comparison matrices that are formed by the expert team. As well, a 5-point scale for defining the preference ratings of alternatives is deliberately adopted as given in Table 4 and Fig. 1.

Table 3. Linguistic terms for the importance weights of the criteria

\begin{tabular}{lccc}
\hline \multicolumn{1}{c}{ Linguistic term } & $\begin{array}{c}\text { Fuzzy } \\
\text { number }\end{array}$ & $\begin{array}{c}\text { Triangular } \\
\text { fuzzy scale }\end{array}$ & $\begin{array}{c}\text { Triangular fuzzy } \\
\text { reciprocal scale }\end{array}$ \\
\hline Equal importance (EI) & $\tilde{1}$ & $(1,1,1)$ & $(1,1,1)$ \\
\hline Intermediate (IMI) & $\tilde{2}$ & $(1,2,3)$ & $(1 / 3,1 / 2,1)$ \\
\hline
\end{tabular}


End of Table 3

\begin{tabular}{lccc}
\hline \multicolumn{1}{c}{ Linguistic term } & $\begin{array}{c}\text { Fuzzy } \\
\text { number }\end{array}$ & $\begin{array}{c}\text { Triangular } \\
\text { fuzzy scale }\end{array}$ & $\begin{array}{c}\text { Triangular fuzzy } \\
\text { reciprocal scale }\end{array}$ \\
\hline Moderate importance (MI) & $\tilde{3}$ & $(2,3,4)$ & $(1 / 4,1 / 3,1 / 2)$ \\
\hline Intermediate (ISI) & $\tilde{4}$ & $(3,4,5)$ & $(1 / 5,1 / 4,1 / 3)$ \\
\hline Strong importance (SI) & $\tilde{5}$ & $(4,5,6)$ & $(1 / 6,1 / 5,1 / 4)$ \\
\hline Intermediate (IVSI) & $\tilde{6}$ & $(5,6,7)$ & $(1 / 7,1 / 6,1 / 5)$ \\
\hline Very strong importance (VSI) & $\tilde{7}$ & $(6,7,8)$ & $(1 / 8,1 / 7,1 / 6)$ \\
\hline Intermediate (IEXI) & $\tilde{8}$ & $(7,8,9)$ & $(1 / 9,1 / 8,1 / 7)$ \\
\hline Extreme importance (EXI) & $\tilde{9}$ & $(8,9,10)$ & $(1 / 10,1 / 9,1 / 8)$ \\
\hline
\end{tabular}

Table 4. Linguistic terms for the preference rating of alternatives

\begin{tabular}{|c|c|}
\hline Linguistic term & Corresponding triangular fuzzy number \\
\hline Very poor $(\mathrm{VP})$ & $(0,1,3)$ \\
\hline Poor $(\mathrm{P})$ & $(1,3,5)$ \\
\hline Fair $(\mathrm{F})$ & $(3,5,7)$ \\
\hline Good (G) & $(5,7,9)$ \\
\hline Very good (VG) & $(7,9,10)$ \\
\hline
\end{tabular}

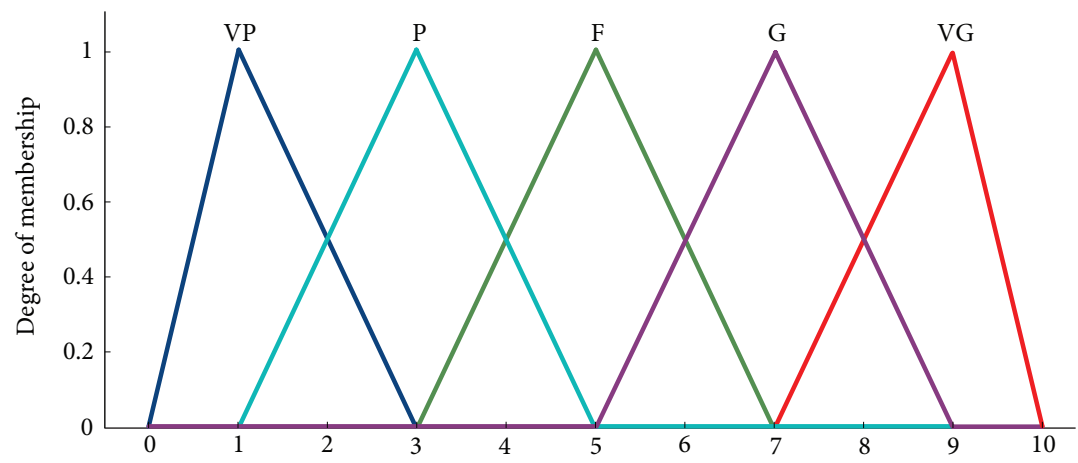

Fig. 1. Membership functions of linguistic values for preference rating

\section{Fuzzy ANP}

Analytic network process (ANP), one of the most comprehensive frameworks of MCDM methods, is applied to identify the effects of the evaluation criteria on each other, to determine their importance. The ANP technique, introduced by Saaty in 1996, is a general form of analytical hierarchy process (AHP). Saaty proposed the use of AHP to solve the problem of independence among alternatives or criteria, and the use of ANP to solve the problem of dependence among alternatives or criteria (Yüksel, Dağdeviren 2010). AHP decomposes a 
complex decision problem into several levels in a structure of hierarchy and then calculates the weight of the factors with the pairwise comparison. This model is formed based on the assumptions of unidirectional, hierarchical relationship among decision levels (Erdoğmus et al. 2005).

Many decision problems cannot be structured hierarchically because they involve the interaction and dependence of higher-level elements in a hierarchy on lower-level elements, therefore creation of a network of elements is needed (Begičević et al. 2010). The ANP method is capable to take into account both interaction and feedback within clusters of elements (inner dependence) and between clusters (outer dependence) (Önüt et al. 2011). The relative weights in a network are obtained similar to the AHP using pairwise comparisons and judgments.

However, the pure ANP technique includes some drawbacks: the ANP approach is mainly employed in decision making problems with precise and accurate information; based on the ANP method, the human judgment in order to obtain relative importance of elements has great influence on the ANP results; and this method does not handle the inherent uncertainty associated with the decision. To overcome these problems, the combination of fuzzy theory with ANP to model the uncertainty, difficulty, and complexity has been proposed

Since the introduction of FANP, it is effectively employed to solve various decision-making problems, such as faulty behavior risk (Dağdeviren et al. 2008); manufacturing (Yüksel, Dağdeviren 2010); container port selection (Önüt et al. 2011); quality function deployment (Liu, Wang 2010); production strategy evaluation (Lee et al. 2010).

In the pair-wise comparison of elements, experts can use TFN to express their preferences. Even though the discrete scale of 1-9 has the advantages of simplicity and easiness for use, it does not take into account the uncertainty associated with the mapping of one's perception or judgment to a number (Önüt et al. 2009). In this approach, pair-wise comparison matrices are formed between the BOCR factors with the help of TFNs. To achieve the aim, a scale of $\tilde{1}-\tilde{9}$ can be defined for TFNs instead of the scale of 1-9 as presented in Table 3.

In order to calculate the weights of BOCR factors, we adopted Chang's extent analysis method (Chang 1996) because the steps of this approach are relatively easier, less time taking and there are less computational expense than the other fuzzy AHP (Van Laarhoven, Pedrycz 1983).

The steps of Chang's extent analysis methods are as follows: Let $\mathrm{X}=\left\{x_{1}, x_{2}, \ldots, x_{n}\right\}$ be an object set, and $\mathrm{U}=\left\{u_{1}, u_{2}, \ldots, u_{m}\right\}$ be a goal set. According to the method of Chang's extent analysis, each object is taken and extent analysis for each goal, $g_{i}$, is performed, respectively. Therefore, $m$ extent analysis values for each object can be obtained, with the following signs:

$$
M_{g i}^{1}, M_{g i}^{2}, \ldots, M_{g i}^{m}, i=1,2, \ldots, n .
$$

Where all the $M_{g i}^{j}(j=1,2, \ldots, m)$ are TFNs.

The steps of Chang's extent analysis can be given as in the following:

Step 1 . The value of fuzzy synthetic extent with respect to $i$ th object is defined as:

$$
S_{i}=\sum_{j=1}^{m} M_{g i}^{j} \otimes\left[\sum_{i=1}^{n} \sum_{j=1}^{m} M_{g i}^{j}\right]^{-1} .
$$


To obtain $\sum_{j=i}^{m} M_{g i}^{j}$, perform the fuzzy addition operation of $m$ extent analysis values for a particular matrix such that

$$
\sum_{j=1}^{m} M_{g i}^{j}=\left(\sum_{j=1}^{m} l_{i}, \sum_{j=1}^{m} m_{i}, \sum_{j=1}^{m} u_{i}\right)
$$

And to obtain $\left[\sum_{i=1}^{n} \sum_{j=1}^{m} M_{g i}^{j}\right]^{-1}$, perform the fuzzy addition operation of $M_{g i}^{j}(j=1,2, \ldots, m)$ values such that

$$
\sum_{i=1}^{n} \sum_{j=1}^{m} M_{g i}^{j}=\left(\sum_{i=1}^{n} l_{i}, \sum_{i=1}^{n} m_{i}, \sum_{i=1}^{n} u_{i}\right) .
$$

And then compute the inverse of the vector in Eq. (5) such that

$$
\left[\sum_{n=1}^{n} \sum_{j=1}^{m} M_{g i}^{j}\right]^{-1}=\left(\frac{1}{\sum_{i=1}^{n} u_{i}}, \frac{1}{\sum_{i=1}^{n} m_{i}}, \frac{1}{\sum_{i=1}^{n} l_{i}}\right) .
$$

Step 2. The degree of possibility of $M_{2}=\left(l_{2}, m_{2}, u_{2}\right) \geq M_{1}=\left(l_{1}, m_{1}, u_{1}\right)$ is defined as

$$
V\left(M_{2} \geq M_{1}\right)=\sup _{y \geq x}\left[\min \left(\mu_{M 1}(x), \mu_{M 2}(y)\right)\right] .
$$

And can be equivalently expressed as follows:

$$
V\left(M_{2} \geq M_{1}\right)=h g t\left(M_{1} \cap M_{2}\right)=\mu_{M 2}(d)= \begin{cases}1, & \text { if } m_{2} \geq m_{1} \\ 0, & \text { if } l_{1} \geq u_{2} \\ \frac{l_{1}-u_{2}}{\left(m_{2}-u_{2}\right)-\left(m_{1}-l_{1}\right)}, & \text { otherwise }\end{cases}
$$

where $d$ is the ordinate of highest intersection point $D$ between $\mu_{M 1}$ and $\mu_{M 2}$ (see Fig. 2).

To compare $M_{1}$ and $M_{2}$, we need both the values of $V\left(M_{1} \geq M_{2}\right)$ and $V\left(M_{2} \geq M_{1}\right)$.

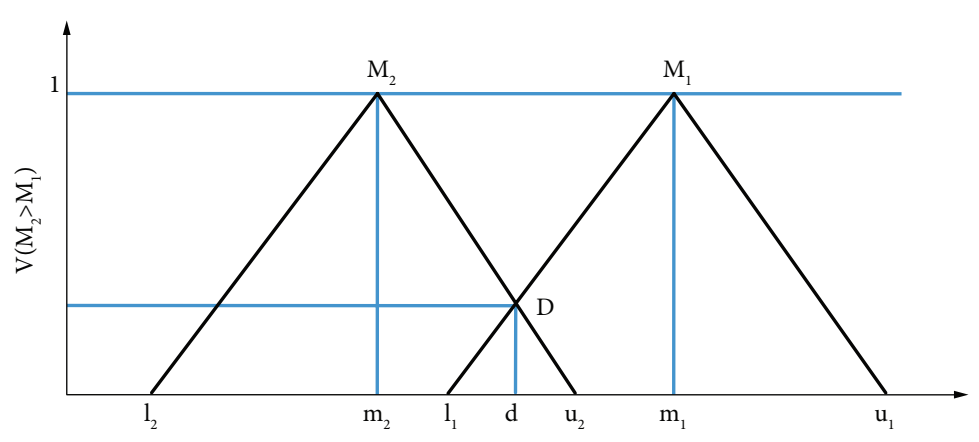

Fig. 2. The intersection between $M_{1}$ and $M_{2}$ (Chang 1996) 
Step 3. The degree of possibility for a convex fuzzy number to be greater than $k$ convex fuzzy numbers $M_{i}(i=1,2, \ldots, k)$ can be defined by

$$
\begin{aligned}
& V\left(M \geq M_{1}, M_{2}, \ldots, M_{k}\right)=V\left[\left(M \geq M_{1}\right) \text { and }\left(M \geq M_{2}\right) \text { and } \ldots\right. \\
& \text { and } \left.\left(M \geq M_{k}\right)\right]=\min V\left(M \geq M_{i}\right), \quad i=1,2, \ldots, k
\end{aligned}
$$

Assume that

$$
d^{\prime}\left(A_{i}\right)=\min V\left(S_{i} \geq S_{k}\right)
$$

For $k=1,2, \ldots, n ; k \neq i$. Then the weight vector is given by

$$
W^{\prime}=\left(d^{\prime}\left(A_{1}\right), d^{\prime}\left(A_{2}\right), \ldots, d^{\prime}\left(A_{n}\right)\right)^{T}
$$

where $A_{i}(i=1,2, \ldots, n)$ are $n$ elements.

Step 4. Via normalization, the normalized weight vectors are

$$
W=\left(d\left(A_{1}\right), d\left(A_{2}\right), \ldots, d\left(A_{n}\right)\right)^{T},
$$

where $W$ is a non-fuzzy number.

\section{Fuzy COPRAS technique}

The COPRAS (COmplex PRoportional ASsessment) method (Zavadskas, Kaklauskas 1996) assumes direct and proportional dependence of the significance and utility degree of the investigated versions in a system of criteria adequately describing the alternatives and of values and weights of the criteria (Zavadskas et al. 2008; Kaklauskas et al. 2010). This method is widely applied when a decision-maker has to select the optimal alternative among a pool of alternatives by considering a set of evaluation criteria.

In the classical COPRAS method, the weights of the criteria and the ratings of alternatives are known precisely and crisp values are employed in the evaluation process. However, under many conditions crisp data are not capable to model real-life decision problems and it is often difficult for evaluators to determine the precise ratings of alternatives and the exact weights of the evaluation criteria. The merit of using a fuzzy approach is to determine the relative importance of attributes using fuzzy numbers instead of precise numbers (Sun 2010). Therefore, the fuzzy COPRAS method is developed to deal with the deficiency in the traditional COPRAS. Fuzzy COPRAS assigns the weights of criteria and ratings of alternatives are evaluated by linguistic terms represented by fuzzy numbers. The procedure of the Fuzzy COPRAS method includes the following steps:

Step 1. Define the linguistic terms. Linguistic terms used by decision maker team are presented in Table 4.

Step 2. Construct the fuzzy decision matrix. The preference ratings of alternatives are expressed with linguistic variables in positive TFNs.

Step 3. Determine the weights of criteria. In this paper, the importance weights of main and sub-criteria are considered as linguistic variables (as shown in Table 3). Due to the existence of dependence and feedback relation between the BOCR factors, in this study, FANP is employed to calculate the importance weights of main criteria. 
Step 4. Determine the aggregated fuzzy rating $\tilde{x}_{i j}$ of alternative $A_{i}, i=1,2, \ldots, m$ under criterion $C_{j}, j=1,2, \ldots, n$.

$$
\begin{aligned}
& \begin{array}{llll}
C_{1} & C_{2} & \cdots & C_{n}
\end{array} \\
& \tilde{D}=\begin{array}{c}
A_{1} \\
A_{2} \\
\vdots \\
A_{m}
\end{array}\left[\begin{array}{cccc}
\tilde{x}_{11} & \tilde{x}_{12} & \cdots & \tilde{x}_{1 n} \\
\tilde{x}_{21} & \tilde{x}_{22} & \vdots & \tilde{x}_{2 n} \\
\vdots & \vdots & \ddots & \vdots \\
\tilde{x}_{m 1} & \tilde{x}_{m 2} & \cdots & \tilde{x}_{m n}
\end{array}\right], i=1,2, \ldots, m ; j=1,2, \ldots n . \\
& \tilde{x}_{i j}=\left(x_{i j 1}, x_{i j 2}, x_{i j 3}\right), \\
& x_{i j 1}=\underset{k}{\min }\left\{x_{i j k 1}\right\}, x_{i j 2}=\frac{1}{K} \sum_{k=1}^{K} x_{i j k 2}, x_{i j 1}=\underset{k}{\max }\left\{x_{i j k 3}\right\} \text {, }
\end{aligned}
$$

where $\tilde{x}_{i j k}$ is the rating of alternative $A_{i}$ with respect to criterion $C_{j}$ evaluated by $k$ th expert (here $k=9), \tilde{x}_{i j k}=\left(x_{i j k 1}, x_{i j k 2}, x_{i j k 3}\right)$.

Step 5. Defuzzify the aggregated fuzzy decision matrix obtained in previous step and derive their crisp values. This research for transformation of the fuzzy weights into the crisp weights applies the center of area method which is a simple and practical method to calculate the best nonfuzzy performance (BNP) value of the fuzzy weights of each dimension. The BNP value of the fuzzy number $\tilde{x}_{i j}$ can be found using Eq. (14):

$$
x_{i j}=\frac{\left[\left(U x_{i j}-L x_{i j}\right)+\left(M x_{i j}-L x_{i j}\right)\right]}{3}+L x_{i j} .
$$

Step 6. Normalize the decision matrix $\left(f_{i j}\right)$. The normalization of the decision making is calculated by dividing each entry by the largest entry in each column to eliminate anomalies with different measurement units, so that all the criteria are dimensionless.

Step 7. Calculate the weighted normalized decision matrix $\left(\hat{x}_{i j}\right)$. The fuzzy weighted normalized values are calculated by multiplying the weight of evaluation indicators $\left(w_{j}\right)$ with normalized decision matrices:

$$
\hat{x}_{i j}=f_{i j} \cdot w_{j} .
$$

Step 8. Sums of attributes values which larger values are more preferable (optimization direction is maximization) calculation for each alternative (line of the decision-making matrix):

$$
P_{i}=\sum_{j=1}^{k} \hat{x}_{i j}
$$

Step 9. Sums $R_{i}$ of attributes values which smaller values are more preferable (optimization direction is minimization) calculation for each alternative (line of the decision-making matrix):

$$
R_{i}=\sum_{j=k+1}^{m} \hat{x}_{i j}
$$

In formula (17) $(m-k)$ there is number of attributes which must be minimized. 
Step 10. Determine the minimal value of $R_{i}$ :

$$
R_{\min }=\min _{i} R_{i} ; i=1, \ldots, n .
$$

Step 11. Calculate the relative weight of each alternative $Q_{i}$ :

$$
Q_{i}=P_{i}+\frac{R_{\min } \sum_{i=1}^{n} R_{i}}{R_{i} \sum_{i=1}^{n} \frac{R_{\min }}{R_{i}}} .
$$

Formula (19) can to be written as follows:

$$
Q_{i}=P_{i}+\frac{\sum_{i=1}^{n} R_{i}}{R_{i} \sum_{i=1}^{n} \cdot \frac{1}{R_{i}}} .
$$

Step 12. Determine the optimality criterion $K$ :

$$
K=\max _{i} Q_{i} ; i=\overline{1, n} \text {. }
$$

Step 13. Assign the priority of the alternatives. The greater weight (relative weight of alternative) $Q_{i}$, the higher is the priority (rank) of the alternatives. In the case of $Q_{\max }$, the satisfaction degree is the highest.

Step 14. Calculate the utility degree of each alternative:

$$
N_{i}=\frac{Q_{i}}{Q_{\max }} 100 \%,
$$

where $Q_{i}$ and $Q_{\max }$ are the weight of projects obtained from Eq. (19).

\section{The proposed model}

The proposed model is defined in the following steps:

Step 1. Identify the evaluation indicators based on the BOCR factors.

Step 2. Structure the ANP model hierarchically.

Step 3. Determine the local weights of the BOCR factors and evaluation indicators by using pairwise comparison matrices (assume that there is no dependence among the BOCR factors). The fuzzy scale regarding relative importance to calculate the relative weights is presented in Table 3. This scale will be utilized in Chang's fuzzy AHP method.

Step 4. Determine, with fuzzy scale (Table 3), the inner dependence matrix of each BOCR factor with respect to the other BOCR factors.

This inner dependence matrix is multiplied with the local weights of the BOCR factors, determined in the previous step, to measure the interdependent weights of the BOCR factors.

Step 5. Compute the global weights for the evaluation indicators. The global weights of evaluation criteria are calculated by multiplying local weight of the evaluation indicators with the interdependent weights of the factors to which it belongs. 
Step 6. Determine the performance ratings of feasible alternatives by linguistic values (Table 4).

Step 7. Calculate the aggregated fuzzy performance ratings.

Step 8. Calculate the performance of working strategies by fuzzy COPRAS based on the global weights obtained in Step 5 for the evaluation indicators and the fuzzy performance ratings determined in previous step.

Step 9. Rank the working strategies determined by fuzzy COPRAS methodology.

Step 10. Select the most appropriate strategy according to the final weights of alternatives.

Schematic diagram of the proposed model for selecting the optimal working strategy is provided in Fig. 3.

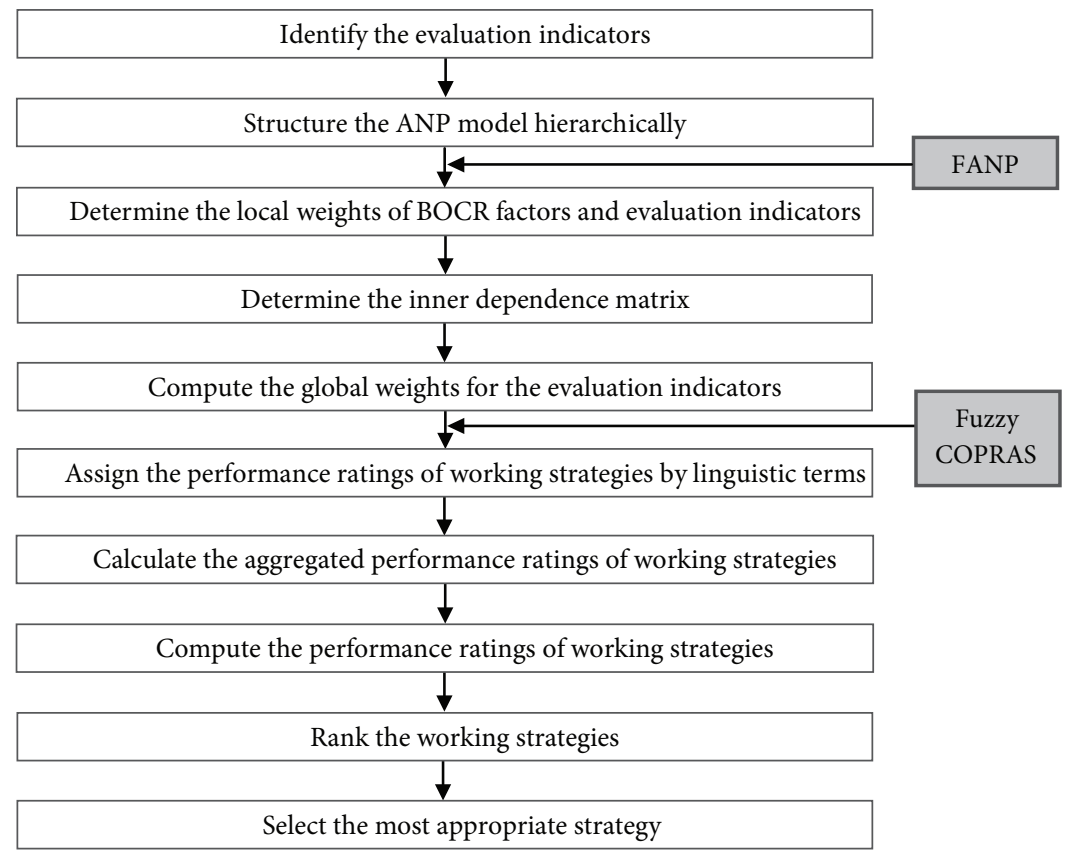

Fig. 3. The steps of fuzzy COPRAS method

\section{The implementation of the proposed model}

The purpose of the empirical application is to illustrate the use of the proposed method. The experiment was setup upon a real world decision problem. Fateh is a construction company in Iran that has been funded in 2005. Fateh offers quality civil construction services in both urban and remote locations. Fateh Company could improve its brand among contractors and has a strong reputation for operational excellence. In order to study different working sectors, a research project entitled "Selecting the most appropriate working strategy" is defined. For achieving the aim, the proposed model, which was fulfilled to Fateh Company, is explained in the following steps. 
Step 1. In the first step, a decision committee is established from nine decision makers with at least 4 year-experience in strategy management who were involved in decision making process. According to semi-structured interviews with decision makers, a list of sixteen strategy process criteria was generated. These sixteen indicators are classified into four as benefit, opportunity, cost, and risk related factors. The group names are accepted as the factors and the sub-factors belonging to these groups are accepted as the evaluation indicators.

The evaluation indicators that are clustered as benefit, opportunity, cost, and risk related are listed in the following part:

Benefit factor includes four elements;

- Profit (BP);

- Credit (BC);

- Flexibility (BF);

- Sustainability (BS);

- Extensibility (BE).

The alternative priorities resulted from benefit indicators represent the intensity of positive contribution imparted by each alternative to the overall decision goal. Therefore, a larger priority value in these indicators corresponds to more benefit of an alternative.

Opportunity factor includes three elements;

- Financial facilities (OF);

- Previous knowledge (OP);

- Existing equipment (OE).

From opportunity indicators, the weights of alternatives represent the level of positive impact each alternative has on the overall decision objective. Therefore, for a particular alternative's priority, the larger it is, the better.

Cost factor includes three elements;

- Initial capital value (CI);

- The existence of competition (CC);

- The need of the skilled labour force (CS);

- The need for new technology (CT).

Based on cost indicators, the weights of alternatives represent the intensity of negative impact each alternative has on the overall decision objective. Therefore, a smaller priority value in these indicators corresponds to less cost of an alternative.

Risk factor includes three elements;

- Financial risk (RF);

- Risk of time delay (RR);

- Demand risk (RD);

- Operating risk (RO).

According to risk indicators, the intensity of negative impact each alternative has on the overall decision objective are obtained based on the weights of alternative. Therefore, for a particular alternative's priority, the smaller it is, the better.

Step 2. The proposed model established by the BOCR factors, evaluation indicators (determined in the previous step), and alternatives are depicted in Fig. 4. FANP model consists of four levels. In the first level of the model, there is the goal to "select the most appropriate 
working strategy". The BOCR factors and the sub-factors (evaluation indicators) related to them are located in second and third levels respectively. The arrows in the second level represent the inner-dependence among the BOCR factors. The BOCR sub-factors in the third level include: five indicators for the benefit factor, three indicators for the opportunity factor, four indicators for the cost factor, and four indicators for the risk factor. Eight alternative strategies proposed for this study are listed in the last level of the model. As depicted in Fig. 4, these alternatives are as follows:

- A1 should be defined as: Constructing a road is a process for establishing a route or way on land between two places, which generally has been flatted or improved to allow travel by motor vehicle.

- A2 should be defined as: Building a bridge in order to span physical obstacles such as valley or road for the goal of providing passage over the obstacle.

- A3 should be defined as: Construction is the process that builds the building.

- A4 should be defined as: Damming is a process that impounds water or underground streams.

- A5 should be defined as: The structures that create a platform for people to work on in order to drill and extract gas or oil at sea.

- A6 should be defined as: A complex of structures and associated facilities for generating electric energy from another source of energy, such as nuclear energy, gas, and hydroelectric dam.

- A7 should be defined as: The petrochemical structures that generate a large number of chemicals made from petroleum or natural gas and the petroleum structures that

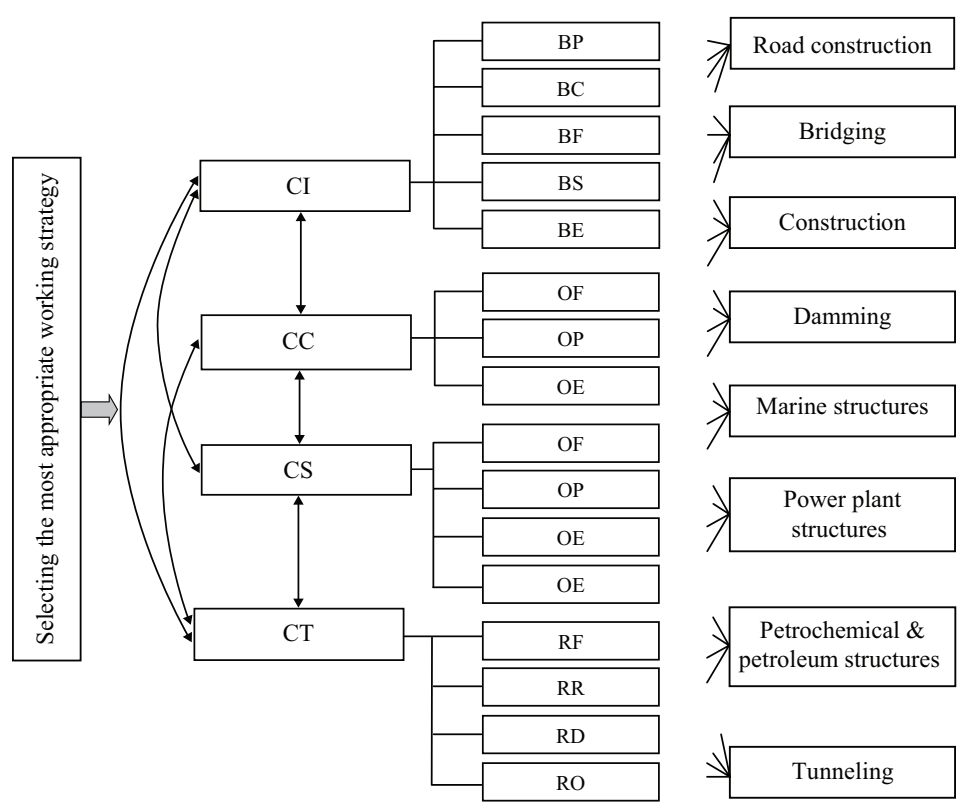

Fig. 4. ANP model 
produce a flammable liquid from the complex mixture of hydrocarbons of various molecular weights and other liquid organic compounds.

- A8 should be defined as: Tunneling is a process that generate an artificial underground space in order to provide a capacity for particular goals such as underground transportation, mine development, and other activities.

Step 3. Assuming that there is no dependence among the BOCR factors, fuzzy pairwise comparison judgement of the BOCR factors using scale presented in Table 3 is made with respect to the goal. These fuzzy pairwise comparisons are established by the decision maker team and the results are depicted in Table 5. For instance, benefit factor (B) and cost factor $(\mathrm{C})$ are compared by asking “How important is ' $\mathrm{B}$ ' when it is compared with ' $\mathrm{C}$ '?” and the answer "EI, EI, IMI, MI, EI, IMI, EI" by nine decision makers, to this linguistic scale is located in the relevant cell against the aggregated fuzzy weights $(1,1.57,4)$. The aggregated fuzzy weights of the BOCR factors and evaluation indicators evaluated by nine experts are calculated through the following relations.

The aggregated fuzzy pairwise comparison matrix $\tilde{w}_{i j} . i, j=1,2, \ldots, n . \tilde{w}_{i j k}$ is the weight of criterion $C_{i}$ in comparison with criterion $C_{j}$ evaluated by $k$-th expert (here $k=9$ ) $\tilde{w}_{i j k}=\left(w_{i j k 1}, w_{i j k 2}, w_{i j k 3}\right)$.

All the fuzzy pairwise comparison matrices are generated in the same way and the results are presented in Tables 6-9. The fuzzy pairwise comparison matrices are evaluated by the Chang's extended analysis method in order to determine the local weights.

$$
\begin{gathered}
\tilde{w}_{i j}=\left(w_{i j 1}, w_{i j 2}, w_{i j 3}\right), \\
\left.w_{i j 1}=\underset{k}{\min \left\{w_{i j k 1}\right\}}\right\} v, \quad w_{i j 2}=\frac{1}{K} \sum_{k=1}^{K} w_{i j k 2}, \quad w_{i j 1}=\max _{k}\left\{w_{i j k 3}\right\},
\end{gathered}
$$

Table 5. Local weights of BOCR factors

\begin{tabular}{lccccc}
\hline BOCR factors & $\mathbf{B}$ & $\mathbf{O}$ & $\mathbf{C}$ & $\mathbf{R}$ & Local weights \\
\hline $\mathrm{B}$ & $(1,1,1)$ & $(2,4.32,6)$ & $(1,1.57,4)$ & $(1,2.42,5)$ & 0.375 \\
\hline $\mathrm{O}$ & $(1 / 6,0.23,0.5)$ & $(1,1,1)$ & $(1 / 4,0.39,1)$ & $(1 / 3,0.86,1)$ & 0.115 \\
\hline $\mathrm{C}$ & $(1 / 4,0.64,1)$ & $(1,2.56,4)$ & $(1,1,1)$ & $(1,2.17,4)$ & 0.31 \\
\hline $\mathrm{R}$ & $(1 / 5,0.41,1)$ & $(1,1.16,3)$ & $(1 / 4,0.46,1)$ & $(1,1,1)$ & 0.2 \\
\hline
\end{tabular}

Table 6. Local weights of benefit sub-factors

\begin{tabular}{lcccccc}
\hline $\begin{array}{c}\text { Benefit } \\
\text { subfactors }\end{array}$ & BP & BC & BF & BS & BE & $\begin{array}{c}\text { Local } \\
\text { weights }\end{array}$ \\
\hline $\mathrm{BP}$ & $(1,1,1)$ & $(1,1.72,5)$ & $(2,3.12,5)$ & $(1,2.16,4)$ & $(3,3.21,6)$ & 0.283 \\
\hline $\mathrm{BC}$ & $(1 / 5,0.58,1)$ & $(1,1,1)$ & $(1 / 3,1.79,4)$ & $(1 / 3,1.34,3)$ & $(1,2.12,4)$ & 0.227 \\
\hline $\mathrm{BF}$ & $(1 / 5,0.32,1 / 2)$ & $(1 / 4,0.59,3)$ & $(1,1,1)$ & $(1 / 3,0.96,3)$ & $(1,1.39,4)$ & 0.194 \\
\hline $\mathrm{BS}$ & $(1 / 4,0.46,1)$ & $(1 / 3,0.74,3)$ & $(1 / 3,1.04,3)$ & $(1,1,1)$ & $(1,2.17,5)$ & 0.213 \\
\hline $\mathrm{BE}$ & $(1 / 6,0.31,1 / 3)$ & $(1 / 4,0.47,1)$ & $(1 / 4,0.72,1)$ & $(1 / 5,0.46,1)$ & $(1,1,1)$ & 0.081 \\
\hline
\end{tabular}


Table 7. Local weights of opportunity sub-factors

\begin{tabular}{lcccc}
\hline Opportunity sub-factors & OF & OP & OE & Local weights \\
\hline OF & $(1,1,1)$ & $(1 / 3,0.87,3)$ & $(1 / 5,0.32,1)$ & 0.282 \\
\hline OP & $(1 / 6,0.23,0.5)$ & $(1,1,1)$ & $(1 / 4,0.67,3)$ & 0.323 \\
\hline OE & $(1 / 4,0.59,1)$ & $(1,2.56,4)$ & $(1,1,1)$ & 0.395 \\
\hline
\end{tabular}

Table 8. Local weights of cost sub-factors

\begin{tabular}{lccccc}
\hline Cost sub-factors & CI & CC & CS & CT & Local weights \\
\hline CI & $(1,1,1)$ & $(2,3.42,6)$ & $(1,1.89,4)$ & $(1 / 3,1.23,3)$ & 0.304 \\
\hline CC & $(1 / 6,0.23,0.5)$ & $(1,1,1)$ & $(1 / 3,0.96,3)$ & $(1 / 5,0.43,1)$ & 0.188 \\
\hline CS & $(1 / 4,0.59,1)$ & $(1,2.56,4)$ & $(1,1,1)$ & $(1 / 4,0.64,3)$ & 0.226 \\
\hline CT & $(1 / 5,0.41,1)$ & $(1,1.16,3)$ & $(1 / 4,0.46,1)$ & $(1,1,1)$ & 0.28 \\
\hline
\end{tabular}

Table 9. Local weights of risk sub-factors

\begin{tabular}{lccccc}
\hline Risk sub-factors & RF & RR & RD & RO & Local weights \\
\hline RF & $(1,1,1)$ & $(1,1.87,4)$ & $(2,3.12,5)$ & $(1,2.34,4)$ & 0.329 \\
\hline RR & $(1 / 6,0.23,0.5)$ & $(1,1,1)$ & $(1,1.61,4)$ & $(1 / 3,1.32,3)$ & 0.252 \\
\hline RD & $(1 / 4,0.59,1)$ & $(1,2.56,4)$ & $(1,1,1)$ & $(1 / 4,0.86,3)$ & 0.181 \\
\hline RO & $(1 / 5,0.41,1)$ & $(1,1.16,3)$ & $(1 / 4,0.46,1)$ & $(1,1,1)$ & 0.236 \\
\hline
\end{tabular}

In order to distinguish the matter, as sample the computations of the local weights of the BOCR factors are presented in the following:

According to the FAHP method, firstly synthesis values must be calculated. From (Table 6), synthesis values respect to main goal are calculated like in Eq. (2):

$$
\begin{aligned}
& S_{B}=(0.028,0.047,0.08) \otimes(5,9.31,16)=(0.14,0.439,1.28), \\
& S_{O}=(0.028,0.047,0.08) \otimes(1.75,2.48,3.5)=(0.049,0.11,0.28), \\
& S_{C}=(0.028,0.047,0.08) \otimes(3.25,6.37,10)=(0.09,0.3,0.8), \\
& S_{R}=(0.028,0.047,0.08) \otimes(2.45,3.03,6)=(0.069,0.143,0.48) .
\end{aligned}
$$

These fuzzy values are compared by using Eq. (7) and these values are obtained:

$V\left(S_{B}>S_{O}\right)=1, V\left(S_{B}>S_{C}\right)=1, \quad V\left(S_{B}>S_{R}\right)=1$,

$V\left(S_{O}>S_{B}\right)=0.303, V\left(S_{O}>S_{C}\right)=0.508, \quad V\left(S_{O}>S_{R}\right)=0.89$,

$V\left(S_{C}>S_{B}\right)=0.826, V\left(S_{C}>S_{O}\right)=1, \quad V\left(S_{C}>S_{R}\right)=1$,

$V\left(S_{R}>S_{B}\right)=0.535, V\left(S_{R}>S_{O}\right)=1, \quad V\left(S_{R}>S_{C}\right)=0.712$.

Then priority weights are calculated by using Eq. (9):

$d^{\prime}(B)=\min (1,1,1)=1$,

$d^{\prime}(O)=\min (0.303,0.508,0.89)=0.303$,

$d^{\prime}(C)=\min (0.826,1,1)=0.826$,

$d^{\prime}(R)=\min (0.535,1,0.712)=0.535$. 
Priority weights form $w_{B O C R}^{\prime}$ factors $=(1,0.303,0.826,0.535)$ vector. After the normalization of these values priority weights respect to main goal are obtained as $(0.375,0.113,0.31,0.2)$. Similar calculations were done for the other fuzzy pairwise comparison matrices and the results of FAHP analyses were summarized in the last column of Tables 5-9.

Step 4. In this step, the dependencies among the BOCR factors are taken into account and interdependent weights of the BOCR factors are computed. In order to determine the dependence among the BOCR factors, the impact of each factor on every other factor using fuzzy pairwise comparisons is evaluated. Based on fuzzy pairwise comparison matrices, Tables 10-13 present the existing dependencies among the BOCR factors. These matrices are formed by asking "What is the relative importance of 'cost factor' when compared with 'risk factor' on controlling 'benefit factor'?” and answers were received from nine decision makers as "EI, IMI, MI, EI, EI, MI, IMI" $(1,1.86,4)$. The resulting relative importance weights are located in the last column of Tables 8-11.

Table 10. The inner dependence matrix of the factors with respect to "Benefit factor"

\begin{tabular}{lcccc}
\hline Benefit factor & $\mathbf{O}$ & $\mathbf{C}$ & $\mathbf{R}$ & Relative importance weights \\
\hline $\mathrm{O}$ & $(1,1,1)$ & $(0.25,0.38,1)$ & $(0.33,0.58,1)$ & 0.204 \\
\hline $\mathrm{C}$ & $(1,2.63,4)$ & $(1,1,1)$ & $(1,1.86,4)$ & 0.461 \\
\hline $\mathrm{R}$ & $(1,1.72,3)$ & $(0.25,0.52,1)$ & $(1,1,1)$ & 0.335 \\
\hline
\end{tabular}

Table 11. The inner dependence matrix of the factors with respect to "Opportunity factor"

\begin{tabular}{lcccc}
\hline Opportunity factor & $\mathbf{B}$ & $\mathbf{C}$ & $\mathbf{R}$ & Relative importance weights \\
\hline $\mathrm{B}$ & $(1,1,1)$ & $(0.33,1.21,3)$ & $(1,1.34,3)$ & 0.365 \\
\hline $\mathrm{C}$ & $(0.33,0.82,3)$ & $(1,1,1)$ & $(0.33,1.17,4)$ & 0.330 \\
\hline $\mathrm{R}$ & $(0.33,0.74,1)$ & $(0.25,0.85,3)$ & $(1,1,1)$ & 0.305 \\
\hline
\end{tabular}

Table 12. The inner dependence matrix of the factors with respect to "Cost factor"

\begin{tabular}{lcccc}
\hline Cost factor & $\mathbf{B}$ & $\mathbf{O}$ & $\mathbf{R}$ & Relative importance weights \\
\hline $\mathrm{B}$ & $(1,1,1)$ & $(1,1.46,4)$ & $(1,2.17,4)$ & 0.430 \\
\hline $\mathrm{O}$ & $(0.25,0.68,1)$ & $(1,1,1)$ & $(0.33,1.23,3)$ & 0.295 \\
\hline $\mathrm{R}$ & $(0.25,0.46,1)$ & $(0.33,0.81,3)$ & $(1,1,1)$ & 0.275 \\
\hline
\end{tabular}

Table 13. The inner dependence matrix of the factors with respect to "Risk factor"

\begin{tabular}{lcccc}
\hline Risk factor & B & O & C & Relative importance weights \\
\hline $\mathrm{B}$ & $(1,1,1)$ & $(0.25,0.67,3)$ & $(0.25,0.46,1)$ & 0.288 \\
\hline $\mathrm{O}$ & $(0.33,1.49,4)$ & $(1,1,1)$ & $(0.33,0.89,3)$ & 0.344 \\
\hline $\mathrm{C}$ & $(1,2.17,4)$ & $(0.33,1.12,3)$ & $(1,1,1)$ & 0.368 \\
\hline
\end{tabular}


Using the calculated relative importance weights, the dependence matrix of the BOCR factors is constructed. Interdependent weights of the BOCR factors are calculated by multiplying the dependence matrix of the BOCR factors with the local weights of the BOCR factors obtained in previous step. The interdependent weights of the BOCR factors are computed in the following part:

$$
\left[\begin{array}{l}
B \\
O \\
C \\
R
\end{array}\right]=\left[\begin{array}{cccc}
1 & 0.365 & 0.430 & 0.288 \\
0.204 & 1 & 0.295 & 0.344 \\
0.461 & 0.330 & 1 & 0.368 \\
0.335 & 0.305 & 0.275 & 1
\end{array}\right] \times\left[\begin{array}{c}
0.375 \\
0.11 \\
0.31 \\
0.20
\end{array}\right]=\left[\begin{array}{c}
0.304 \\
0.176 \\
0.297 \\
0.223
\end{array}\right] .
$$

As shown above, the results are significantly different from when the interdependent weights and dependencies are not taken into account. The final results change from 0.375 to $0.304,0.11$ to $0.176,0.31$ to 0.297 , and 0.20 to 0.223 for the priority values of factors $\mathrm{B}, \mathrm{O}$, $\mathrm{C}$ and $\mathrm{R}$, respectively.

Step 5. In this step, the overall weights of the evaluation indicators are calculated by multiplying the interdependent weights of BOCR factors found in previous step with the local weights of evaluation indicators obtained in Step 3. The overall weights have indicated for each indicator in Table 14 and Fig. 5.

Based on the overall weights listed in Table 14, the most and the least important indicators which can affect the working strategy are "Initial capital value" and "Extensibility",

Table 14. Overall weight of the evaluation indicators

\begin{tabular}{|c|c|c|c|c|}
\hline BOCR factors & $\begin{array}{l}\text { Weight of } \\
\text { the factors }\end{array}$ & Evaluation indicators & $\begin{array}{c}\text { Local } \\
\text { weights }\end{array}$ & $\begin{array}{c}\text { Global } \\
\text { weights }\end{array}$ \\
\hline \multirow[t]{5}{*}{ Benefit (B) } & 0.304 & Profit (BP) & 0.283 & 0.086 \\
\hline & & Credit (BC) & 0.227 & 0.069 \\
\hline & & Flexibility (BF) & 0.194 & 0.059 \\
\hline & & Sustainability (BS) & 0.213 & 0.065 \\
\hline & & Extensibility (BE) & 0.081 & 0.025 \\
\hline \multirow[t]{3}{*}{ Opportunity $(\mathrm{O})$} & 0.176 & Financial facilities (OF) & 0.282 & 0.050 \\
\hline & & Previous knowledge (OP) & 0.323 & 0.057 \\
\hline & & Existing equipment $(\mathrm{OE})$ & 0.395 & 0.069 \\
\hline \multirow[t]{4}{*}{ Cost $(\mathrm{C})$} & 0.297 & Initial capital value $(\mathrm{CI})$ & 0.304 & 0.090 \\
\hline & & The existence of competition (CC) & 0.188 & 0.056 \\
\hline & & The need of the skilled labour force (CS) & 0.226 & 0.067 \\
\hline & & The need for new technology (CT) & 0.28 & 0.083 \\
\hline \multirow[t]{4}{*}{ Risk (R) } & 0.223 & Financial risk (RF) & 0.329 & 0.073 \\
\hline & & Risk of time delay (RR) & 0.252 & 0.056 \\
\hline & & Demand risk $(\mathrm{RD})$ & 0.181 & 0.040 \\
\hline & & Operating risk (RO) & 0.236 & 0.053 \\
\hline
\end{tabular}




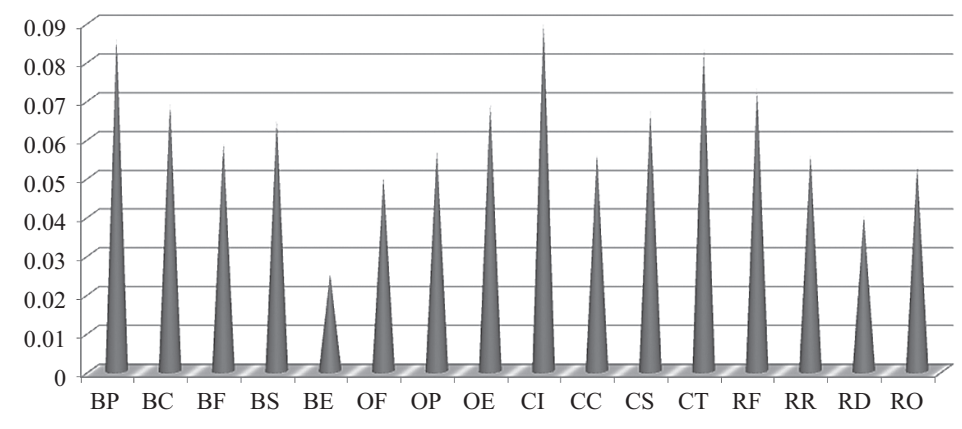

Fig. 5. Final weights of evaluation indicators

respectively. As well as, under the benefit sub-factors, the most important indicator, out of the five indicators, is "Profit", with a weight of 0.086 . This means that the major benefit concern for the company in selecting the optimal working strategy is to have a high profit of the activities. Furthermore, under the opportunity sub-factors, "existing equipment" with a priority of 0.069 is the most important indicator. This means that a working strategy which can use existent equipment and facilities is in a high priority for the company.

Besides, under the cost sub-factors, "initial capital value" with a weight of 0.09 is the most significant indicator. This implies that initial capital is more important than other evaluation indicators in order to select the most appropriate working strategy. Finally, under the risk sub-factors, "financial risk" with a value of 0.073 causes the problem that the company worries about. This implies that the company is more concerned about any risk associated with any form of financing.

Step 6. In this step, the fuzzy performance results from various alternatives under different criteria that are collected from each expert individually in order to limit the number of pairwise comparisons. For the evaluation indicators under benefit and opportunity factors (BP, BC, BF, BS, BE, OF, OP, and OE), the higher the score, the better the performance of the working strategy is. Whereas, for the indicators under cost and risk factors (CI, CC, CS, CT, RF, $\mathrm{RR}, \mathrm{RD}$, and $\mathrm{RO}$ ), the higher the score, the worse the performance of the working strategy is.

For this reason, experts were asked to form fuzzy decision matrix by linguistic variables presented in Table 4. It is constructed by comparing eight alternatives under sixteen evaluation indicators separately. For example, the fuzzy decision matrix filled by one of the decision makers is presented in Table 15.

Step 7. In this step, the aggregated fuzzy performance ratings of working strategies with respect to each criterion are computed by Eq. (13) and the results are presented in Table 16.

Step 8. In this step, the aggregated fuzzy performance ratings are defuzzified by Eq. (14) to derive their crisp values. In order to normalize the current decision matrix, the performance ratings are transferred into a number between zero to one by dividing the performance rating of a working strategy on a criterion by the largest performance rating among all working strategies on the same criterion. Then, the weighted normalized decision matrix can be calculated by multiplying the importance weights of evaluation indicators and the values in the normalized decision matrix as shown in Table 17. According to the fuzzy COPRAS 
technique, the maximizing and minimizing indexes for each alternative are calculated by using Eqs. (16) and (17), as presented in Table 18. In the last phase of this step, the relative weight and the utility degree of each alternative are calculated as presented in Table 18.

Step 9. In this step, the working strategies are ranked as shown in Table 18 and Fig. 6. According to $N$ values, the ranking of the alternatives in descending order are A6, A3, A7, A1, A5, A2, A8, and A4.

Step 10. In the last step, according to the final weights of alternatives, the optimum working strategy is selected. As seen in Table 18, power plant structures (A6) is first in the list of priorities, while damming (A4) is the fourth.

Table 15. A sample of fuzzy evaluation matrix evaluated by one of the experts

\begin{tabular}{ccccccccc}
\hline & A1 & A2 & A3 & A4 & A5 & A6 & A7 & A8 \\
\hline BP & VG & G & VG & F & VG & G & VG & G \\
\hline BC & F & G & P & VG & VG & VG & VG & G \\
\hline BF & P & VG & G & VG & G & P & VG & VP \\
\hline BS & F & VG & VG & VG & G & F & VG & G \\
\hline BE & G & G & VG & VG & VG & F & G & P \\
\hline OF & VG & P & VG & VG & F & G & F & F \\
\hline OP & P & G & P & VP & P & P & P & G \\
\hline OE & VG & F & P & VP & VP & P & VP & G \\
\hline CI & G & G & P & F & P & VP & P & G \\
\hline CC & G & G & VG & VP & VP & VP & VP & P \\
\hline CS & P & G & F & VG & G & VG & VG & G \\
\hline CT & P & F & VG & G & VG & VG & VG & G \\
\hline RF & F & F & VP & G & F & P & VP & VG \\
\hline RR & VG & G & P & VG & G & F & G & F \\
\hline RD & P & P & VP & G & VG & VG & VG & F \\
\hline RO & VG & G & P & G & P & P & P & G \\
\hline & & & & & & & &
\end{tabular}

Table 16. The aggregated fuzzy evaluation matrix

\begin{tabular}{|c|c|c|c|c|c|c|}
\hline & A1 & A2 & A4 & A6 & A7 & A8 \\
\hline $\mathrm{BP}$ & $(5,8$. & $(3,6$. & $(1,4.36,7)$ & $(3,7.12$ & ( & ) \\
\hline $\mathrm{BC}$ & $1,5.2$ & 1.0 & $(0,2.78,7)(5,8.16,10)$ & $(3,7.23,10)(5,8.23,10)$ & $(3,7.89,10)$ & \\
\hline $\mathrm{BF}$ & $, 4.23,7)$ & $(3,7.12,1$ & $(3,6.81,10)(5,7.23,1$ & $(3,6.85,10) \quad(1,4.46,7)$ & $(3,6.65,10)$ & $(0,2.21,5)$ \\
\hline BS & $(1,5.16,7)$ & $(3,7.41,10$ & $(5,8.09,10)(3,7.31,10)$ & $(3,6.52,10)(3,5.68,9)$ & $(3,8.12,10)$ & $(3,6.77,9)$ \\
\hline $\mathrm{BI}$ & $(5,7.89,1$ & $(3,6.92,10$ & $(3,6.96,10)(5,7.87,10$ & $(5,8.34,10)(1,3.83,7)$ & $(3,7.21,10)$ & $(0,2$. \\
\hline OF & $(5,7.34,10)$ & $(1,3.43,7)$ & $(5,7.21,10)(5,8.12,10)$ & $(1,4.34,7) \quad(3,7.26,10)$ & $(1,5.32,9)$ & $(1,4.67,7)$ \\
\hline $\mathrm{OP}$ & $(0,3.21,7)$ & $(3,5.34,9)$ & $(0,3.23,7) \quad(0,2.12,5)$ & $(0,3.16,7) \quad(1,4.34,7)$ & $(0,3.46,7)$ & $(3,7.34,10)$ \\
\hline $\mathrm{OE}$ & $(5,8.42,10)$ & $(1,4.78,9)$ & $(0,2.34,5) \quad(0,1.67,5)$ & $(0,2.16,7) \quad(1,4.46,9)$ & $(0,1.87,5)$ & $(3,6.67,10)$ \\
\hline $\mathrm{CI}$ & $(3,7.23,10)$ & $(5,7.46,10)$ & $(1,4.57,7) \quad(1,4.87,9)$ & $(1,4.67,7) \quad(0,2.31,5)$ & $(0,3.16,7)$ & $(3,6.43,10)$ \\
\hline $\mathrm{CC}$ & $(3,5.23,9)$ & $(3,6.42,10$ & $(5,7.56,10)(0,2.36,5)$ & $(0,2.14,7) \quad(0,1.67,5)$ & $(0,1.89,5)$ & $(0,3.23,7)$ \\
\hline $\mathrm{CS}$ & $(1,4.46,7)$ & $(3,6.54,9)$ & $(1,3.21,7)(5,7.46,10)$ & $(3,6.78,9) \quad(3,7.34,10)$ & $(5,7.78,10)$ & $(3,5.47,9)$ \\
\hline $\mathrm{CT}$ & $(0,3.21,7)$ & $(1,4.67,7)$ & $(5,8.24,10)(3,6.72,10)$ & $(5,8.24,10)(5,7.54,10)$ & $(3,7.67,10)$ & $(3,6.31,9)$ \\
\hline $\mathrm{RF}$ & $(1,4.32,7)$ & $(3,5.54,9)$ & $(0,1.63,5) \quad(3,5.67,9)$ & $(1,4.56,9) \quad(0,1.89,5)$ & $(0,2.12,7)$ & $(5,7.62,10)$ \\
\hline
\end{tabular}


End of Table 16

\begin{tabular}{cccccccc}
\hline A1 & A2 & A3 & A4 & A5 & A6 & A7 & A8 \\
\hline RR $(3,6.57,10)$ & $(3,5.27,9)$ & $(0,2.56,7)$ & $(5,7.76,10)$ & $(3,6.12,10)$ & $(3,5.43,9)$ & $(3,7.42,10)$ & $(1,4.57,9)$ \\
\hline $\operatorname{RD}(1,4.23,9)$ & $(0,1.67,5)$ & $(0,2.16,5)$ & $(3,6.44,9)$ & $(3,6.87,10)$ & $(5,7.57,10)$ & $(5,8.21,10)$ & $(1,4.23,7)$ \\
\hline $\operatorname{RO}(5,7.89,10)$ & $(3,5.96,9)$ & $(0,3.34,9)$ & $(3,5.57,9)$ & $(0,1.84,5)$ & $(0,2.12,5)$ & $(1,3.67,7)$ & $(3,6.17,9)$ \\
\hline
\end{tabular}

Table 17. The weighted normalized decision matrix of eight working strategies

\begin{tabular}{ccccccccc}
\hline & A1 & A2 & A3 & A4 & A5 & A6 & A7 & A8 \\
\hline BP & 0.086 & 0.072 & 0.073 & 0.046 & 0.084 & 0.074 & 0.085 & 0.072 \\
\hline BC & 0.045 & 0.066 & 0.029 & 0.069 & 0.060 & 0.069 & 0.062 & 0.059 \\
\hline BF & 0.032 & 0.053 & 0.053 & 0.059 & 0.053 & 0.033 & 0.052 & 0.019 \\
\hline BS & 0.037 & 0.057 & 0.065 & 0.057 & 0.055 & 0.050 & 0.059 & 0.053 \\
\hline BE & 0.025 & 0.021 & 0.021 & 0.024 & 0.025 & 0.013 & 0.022 & 0.008 \\
\hline OF & 0.048 & 0.025 & 0.048 & 0.050 & 0.027 & 0.044 & 0.033 & 0.027 \\
\hline OP & 0.029 & 0.049 & 0.029 & 0.020 & 0.028 & 0.035 & 0.029 & 0.057 \\
\hline OE & 0.069 & 0.044 & 0.022 & 0.020 & 0.027 & 0.043 & 0.020 & 0.058 \\
\hline CI & 0.081 & 0.090 & 0.050 & 0.060 & 0.051 & 0.029 & 0.041 & 0.078 \\
\hline CC & 0.043 & 0.048 & 0.056 & 0.018 & 0.023 & 0.017 & 0.017 & 0.025 \\
\hline CS & 0.037 & 0.055 & 0.033 & 0.066 & 0.055 & 0.060 & 0.067 & 0.051 \\
\hline CT & 0.036 & 0.045 & 0.083 & 0.070 & 0.083 & 0.081 & 0.074 & 0.065 \\
\hline RF & 0.040 & 0.057 & 0.021 & 0.057 & 0.047 & 0.022 & 0.029 & 0.073 \\
\hline RR & 0.048 & 0.042 & 0.024 & 0.056 & 0.047 & 0.043 & 0.050 & 0.036 \\
\hline RD & 0.025 & 0.011 & 0.012 & 0.032 & 0.034 & 0.039 & 0.040 & 0.021 \\
\hline RO & 0.053 & 0.042 & 0.029 & 0.041 & 0.016 & 0.016 & 0.027 & 0.042 \\
\hline & & & & & & & &
\end{tabular}

Table 18. Fuzzy COPRAS results

\begin{tabular}{lcccccccc}
\hline & A1 & A2 & A3 & A4 & A5 & A6 & A7 & A8 \\
\hline$P_{i}$ & 0.371 & 0.388 & 0.339 & 0.345 & 0.359 & 0.360 & 0.363 & 0.353 \\
\hline$R_{i}$ & 0.362 & 0.390 & 0.308 & 0.400 & 0.356 & 0.307 & 0.345 & 0.392 \\
\hline$Q_{i}$ & 0.721 & 0.712 & 0.750 & 0.661 & 0.715 & 0.773 & 0.729 & 0.676 \\
\hline$N$ & 93.263 & 92.190 & 97.116 & 85.599 & 92.484 & 100.000 & 94.380 & 87.515 \\
\hline Rank & 4 & 6 & 2 & 8 & 5 & 1 & 3 & 7 \\
\hline
\end{tabular}

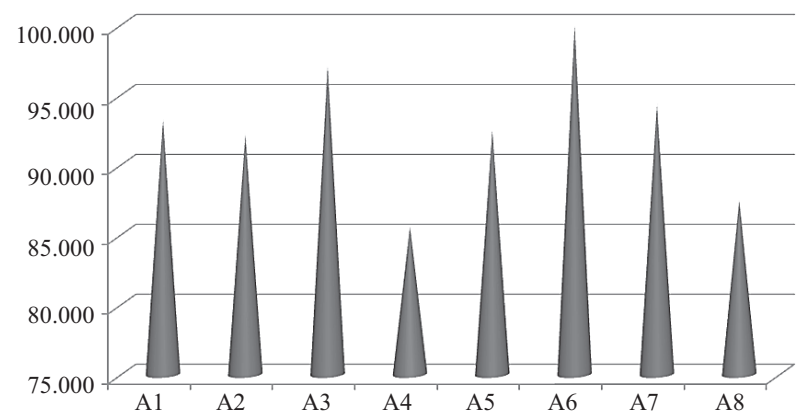

Fig. 6. Ranking of working strategies 


\section{Sensitivity analysis}

Sensitivity analysis is a powerful tool for evaluating the proposed model in order to calculate the stability of the results by changing the priorities of the BOCR factors and reflect the strength of the constructed model. In this paper, the priorities for BOCR factors are changed one at a time to perform sensitivity analysis, and the changing range is from 0 to 1 . Figs. 7, 8, 9, and 10 depict the sensitivity analysis graph when the priority of benefits, opportunities, costs and risks changes, respectively.

For example, the original priority of benefit (B) is 0.304 , and a trial and error method is employed to calculate how the priorities of alternatives are correlated with changes in $\mathrm{B}$ values. As shown in Fig. 7, while the weight of the benefits increases; the share of A7 increases, whereas the share of A6 decreases. The analysis of the benefit factor shows that A4, A7, A2, and A5 have positive features, whereas A8, A1 and A6 have negative features. As weight of the benefit increases, the benefit related with the profit positively affects theshare of A4, A7, $\mathrm{A} 2$, and A5. It can be also seen that the results are very sensitive to the changes in the weight of the benefit, and the rank of the alternatives changes from "A6 $\succ \mathrm{A} 3 \succ \mathrm{A} 1 \succ \mathrm{A} 8 \succ \mathrm{A} 7 \succ$ $\mathrm{A} 2 \succ \mathrm{A} 5 \succ \mathrm{A} 4$ " (for \% benefit weight) to "A7 $\succ \mathrm{A} 5 \succ \mathrm{A} 2 \succ \mathrm{A} 6 \succ \mathrm{A} 3 \succ \mathrm{A} 4 \succ \mathrm{A} 1 \succ \mathrm{A} 8$ " (for $100 \%$ benefit weight).

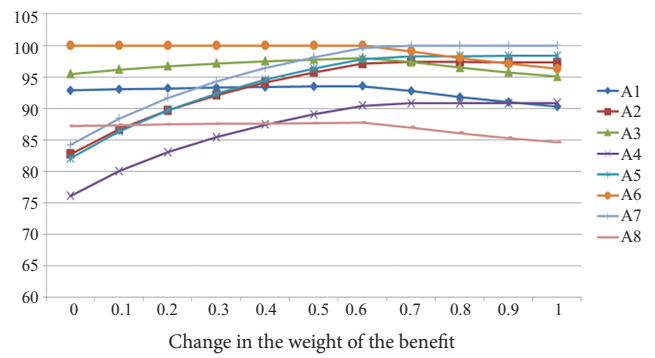

Fig. 7. Sensitivity analysis results with respect to Benefit factor

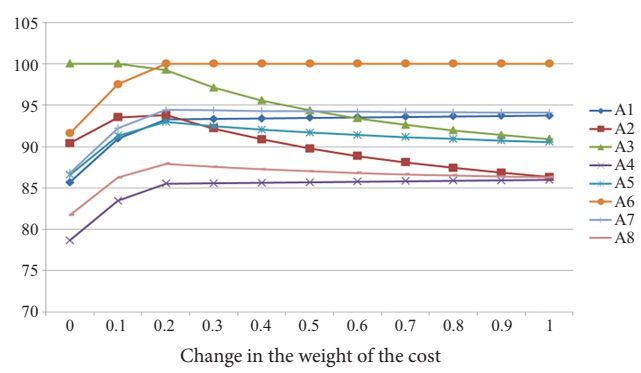

Fig. 9. Sensitivity analysis results with respect to Cost factor

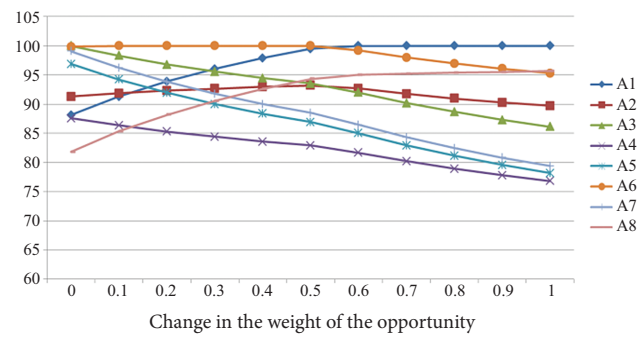

Fig. 8. Sensitivity analysis results with respect to Opportunity factor

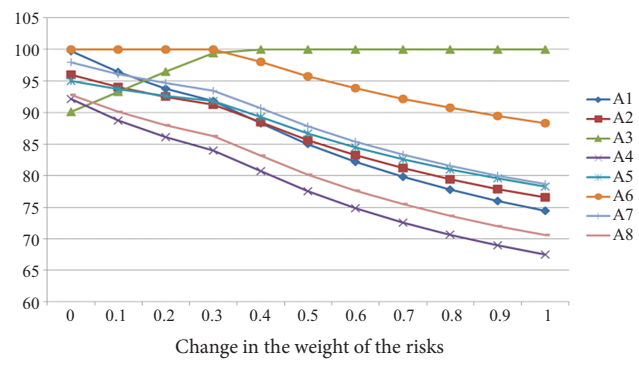

Fig. 10. Sensitivity analysis results with respect to Risk factor 
Moreover, when $\mathrm{O}$ increases to 1, the optimum working strategy changes from A6 to A1 (as depicted in Fig. 8). In other words, the best alternative becomes A1 when O increases to 1 . When $\mathrm{C}$ increases to 1, the optimum working strategy changes from A3 to A6 (as seen in Fig. 9). As presented in Fig. 10, the optimum working strategy changes from A6 to A3, while $\mathrm{R}$ increases from 0 to 1.

\section{Conclusion}

The working strategy selection problem is an important issue and has significant impacts to the continuity of a company. Decision makers to simultaneously pursue increased incomes and decreased costs should select the best working strategy among a pool of feasible working strategies. To achieve the aim, different types of alternatives are evaluated with the consideration of the benefit, opportunity, cost and risk (BOCR) factors. This leads to inter-relationship among factors and a large set of vague and imprecise data. For this reason, developing an efficient evaluation technique in order to improve decision quality is necessary.

In this study, an integrated framework to evaluate working strategies is proposed, which uses linguistic terms to take into consideration the subjective judgments of experts and then it adopts FANP and fuzzy COPRAS to evaluate the decision making problem. The priorities of BOCR factors are obtained by FANP based on pairwise comparison matrix so that the inter-relationship among factors and the linguistic uncertainty of evaluators can be incorporated in the computation. In order to determine the priorities of the alternatives, fuzzy COPRAS is employed. Fuzzy COPRAS eliminates many procedures to be performed only in FANP methodology and enables decision maker to reach a conclusion in a shorter time. Then the proposed model is tested by a real case study of working strategy selection in an Iranian construction company. Through the implementation of the model, the authorities and decision makers can understand the merits of different working strategies and the reasons behind why a working strategy should be selected. A sensitivity analysis is also carried out to measure the stability of the results. The results of sensitivity analysis show that the preferences of alternatives vary from the original when the values of benefit, opportunity, cost or risk are changed. Although the model was proposed for the use in working strategy selection problem, it can also be used in other multi-criteria decision making problems in strategic management.

\section{References}

Antucheviciene, J.; Zakarevicius, A.; Zavadskas, E. K. 2011. Measuring congruence of ranking results applying particular MCDM methods, Informatica 22(3): 319-333.

Bashiri, M.; Badri, H.; Hejazi, T. H. 2011. Selecting optimum maintenance strategy by fuzzy interactive linear assignment method, Applied Mathematical Modelling 35(1): 152-164. http://dx.doi.org/10.1016/j.apm.2010.05.014

Begičević, N.; Divjak, B.; Hunjak, T. 2010. Decision-making on prioritization of projects in higher education institutions using the analytic network process approach, Central European Journal of Operations Research 18: 341-364. http://dx.doi.org/10.1007/s10100-009-0113-3 
Bobylev, N. 2011. Comparative analysis of environmental impacts of selected underground construction technologies using the analytic network process, Automation in Construction 20(8): 1030-1040. http://dx.doi.org/10.1016/j.autcon.2011.04.004

Bottero, M.; Ferretti, V. 2011. An analytic network process-based approach for location problems: the case of a new waste incinerator plant in the province of Torino (Italy), Journal of Multi-Criteria Decision Analysis 17: 63-84. http://dx.doi.org/10.1002/mcda.456

Chang, D. Y. 1996. Applications of the extent analysis method on fuzzy AHP, European Journal of Operational Research 95: 649-655. http://dx.doi.org/10.1016/0377-2217(95)00300-2

Chatterjee, P.; Athawale, V. M.; Chakraborty, S. 2011. Materials selection using complex proportional assessment and evaluation of mixed data methods, Materials and Design 32(2): 851-860. http://dx.doi.org/10.1016/j.matdes.2010.07.010

Chatterjee, P.; Chakraborty, S. 2011. Material selection using preferential ranking methods, Materials and Design 35: 384-393. http://dx.doi.org/10.1016/j.matdes.2011.09.027

Chen, H. H.; Lee, A. H. I.; Kang, H. Y. 2010. A model for strategic selection of feeder management systems: a case study, Electrical Power and Energy Systems 32: 421-427. http://dx.doi.org/10.1016/j.ijepes.2009.09.023

Dağdeviren, M.; Yüksel, İ.; Kurt, M. 2008. A fuzzy analytic network process (ANP) model to identify faulty behavior risk (FBR) in work system, Safety Science 46(5): 771-783. http://dx.doi.org/10.1016/j.ssci.2007.02.002

Erdoğmus, Ş.; Kapanoglu, M.; Koç, E. 2005. Evaluating high-tech alternatives by using analytic network process with BOCR and multiactors, Evaluation and Program Planning 28: 391-399. http://dx.doi.org/10.1016/j.evalprogplan.2005.07.003

Kaklauskas, A.; Zavadskas, E. K.; Naimavicienė, J.; Krutinis, M.; Plakys, V.; Venskus, D. 2010. Model for a complex analysis of intelligent built environment, Automation in Construction 19: 326-340. http://dx.doi.org/10.1016/j.autcon.2009.12.006

Kildiene, S.; Kaklauskas, A.; Zavadskas, E. K. 2011. COPRAS based comparative analysis of the European country management capabilities within the construction sector in the time of crisis, Journal of Business Economics and Management 12(2): 417-434. http://dx.doi.org/10.3846/16111699.2011.575190

Lee, A. H. I.; Chen, H. H.; Kang, H. Y. 2011. A model to analyze strategic products for photovoltaic silicon thin-film solar cell power industry, Renewable and Sustainable Energy Reviews 15: 1271-1283. http://dx.doi.org/10.1016/j.rser.2010.10.008

Lee, A. H. I.; Lin, Ch. Y.; Wang, Sh. R.; Tu, Y. M. 2010. The construction of a comprehensive model for production strategy evaluation, Fuzzy Optim Decis Making 9: 187-217. http://dx.doi.org/10.1007/s10700-010-9077-y

Liu, H. T.; Wang, Ch. H. 2010. An advanced quality function deployment model using fuzzy analytic network process, Applied Mathematical Modelling 34(11): 3333-3351. http://dx.doi.org/10.1016/j.apm.2010.02.024

Maniya, K. D.; Bhatt, M. G. 2011. An application of integrated multi criteria decision making (AHP/ COPRAS) model for ranking and selection of flexible manufacturing systems, Journal of Manufacturing Engineering 6(1): 30-35.

Medineckiene, M.; Björk, F. 2011. Owner preferences regarding renovation measures - the demonstration of using multi-criteria decision making, Journal of Civil Engineering and Management 17(2): 284-295.

Önüt, S.; Tuzkaya, U. R.; Torun, E. 2011. Selecting container port via a fuzzy ANP-based approach: a case study in the Marmara Region, Turkey, Transport Policy 18(1): 182-193. http://dx.doi.org/10.1016/j.tranpol.2010.08.001

Önüt, S.; Kara, S. S.; Işik, E. 2009. Long term supplier selection using a combined fuzzy MCDM approach: a case study for a telecommunication company, Expert Systems with Applications 36: 3887-3895. http://dx.doi.org/10.1016/j.eswa.2008.02.045 
Presley, A.; Meade, L. 1999. Strategic allignment and IT investment selection using the analytic network process. Paper presented at the Americas Conference on information systems. Milwaukee WI.

Saaty, T. L. 1996. Decision Making with Dependence and Feedback: the Analytic Network Process. Pittsburgh: RWS Publications.

Sun, Ch. Ch. 2010. A performance evaluation model by integrating fuzzy AHP and fuzzy TOPSIS methods, Expert Systems with Applications 37(12): 7745-7754. http://dx.doi.org/10.1016/j.eswa.2010.04.066

Tupenaite, L.; Zavadskas, E. K.; Kaklauskas, A.; Turskis, Z.; Seniut, M. 2010. Multiple criteria assessment of alternatives for built and human environment renovation, Journal of Civil Engineering and Management 16(2): 257-266. http://dx.doi.org/10.3846/jcem.2010.30

Vahdani, B.; Hadipour, H. 2010. Extension of VIKOR method based on interval-valued fuzzy sets, International Journal of Advanced Manufacturing Technology 47: 1231-1239. http://dx.doi.org/10.1007/s00170-009-2241-2

Van Laarhoven, P. J. M.; Pedrycz, W. 1983. A fuzzy extension of Saaty's priority theory, Fuzzy Sets and Systems 11: 229-241.

Wu, Ch. Sh.; Lin, Ch. T.; Lee, Ch. 2010. Optimal marketing strategy: a decision-making with ANP and TOPSIS, International Journal of Production Economics 127: 190-196. http://dx.doi.org/10.1016/j.ijpe.2010.05.013

Yazdani, M.; Alidoosti, A.; Zavadskas, E. K. 2011. Risk analysis of critical infrastructures using fuzzy COPRAS, Ekonomska Istraživanja - Economic Research 24(4): 27-40.

Yazgan, H. R.; Boran, S.; Goztepe, K. 2010. Selection of dispatching rules in FMS: ANP model based on BOCR with choquet integral, International Journal Advanced Manufacturing Technology 49: 785-801. http://dx.doi.org/10.1007/s00170-009-2416-x

Yüksel, İ.; Dağdeviren, M. 2010. Using the fuzzy analytic network process (ANP) for Balanced Scorecard (BSC): a case study for a manufacturing firm, Expert Systems with Applications 37: 1270-1278. http://dx.doi.org/10.1016/j.eswa.2009.06.002

Zadeh, L. A. 1965. Fuzzy sets, Information and Control 8: 338-353. http://dx.doi.org/10.1016/S0019-9958(65)90241-X

Zavadskas, E. K.; Antucheviciene, J. 2007. Multiple criteria evaluation of rural building's regeneration alternatives, Building and Environment 42(1): 436-451. http://dx.doi.org/10.1016/j.buildenv.2005.08.001

Zavadskas, E. K.; Kaklauskas, A. 1996. Determination of an efficient contractor by using the new method of multicriteria assessment, in Langford, D. A.; Retik, A. (Eds.). International Symposium for "The Organisation and Management of Construction". Shaping Theory and Practice. Vol. 2. Managing the Construction Project and Managing Risk. CIB W 65. London, Weinheim, New York, Tokyo, Melbourne, Madras. London: E and FN SPON, 94-104.

Zavadskas, E. K.; Kaklauskas, A.; Turskis, Z.; Tamošaitienè, J. 2008. Selection of the effective dwelling house walls by applying attributes values determined at intervals, Journal of Civil Engineering and Management 14(2): 85-93. http://dx.doi.org/10.3846/1392-3730.2008.14.3

Zolfani Hashemkhani, S.; Rezaeiniya, N.; Zavadskas, E. K.; Turskis, Z. 2011. Forest roads locating based On AHP and COPRAS-G methods: An empirical study based on Iran, E+M Ekonomie a Management 14(4): 6-21.

Mohammad Majid FOULADGAR. Master of Science in the Department of Strategic Management, Manager of Fateh Reaserch Group, Tehran-Iran. Author of 10 research papers. In 2007 he graduated from the Science and Engineering Faculty at Tarbiat Modares University, Tehran-Iran. His interests include decision support system, water resource, and forecasting. 
Abdolreza YAZDANI-CHAMZINI. Master of Science in the Department of Strategic Management, research assistant of Fateh Reaserch Group, Tehran-Iran. Author of more than 20 research papers. In 2011 he graduated from the Science and Engineering Faculty at Tarbiat Modares University, Tehran-Iran. His research interests include decision making, forecasting, modeling, and optimization.

Edmundas Kazimieras ZAVADSKAS. Prof., Head of the Department of Construction Technology and Management at Vilnius Gediminas Technical University, Vilnius, Lithuania. He has a PhD in Building Structures (1973) and Dr Sc. (1987) in Building Technology and Management. He is a member of the Lithuanian and several foreign Academies of Sciences. He is Doctore Honoris Causa at Poznan, Saint-Petersburg, and Kiev universities as well as a member of international organisations; he has been a member of steering and programme committees at many international conferences. E. K. Zavadskas is a member of editorial boards of several research journals. He is the author and co-author of more than 400 papers and a number of monographs in Lithuanian, English, German and Russian. Research interests are: building technology and management, decision-making theory, automation in design and decision support systems.

S. Hamzeh HAJI MOINI. Master of Science of Project Management, research assistant of Fateh Reaserch Group, Tehran-Iran. He is the author of 5 research papers. His interests include decision support system, portfolio selection, and artificial intelligence. 